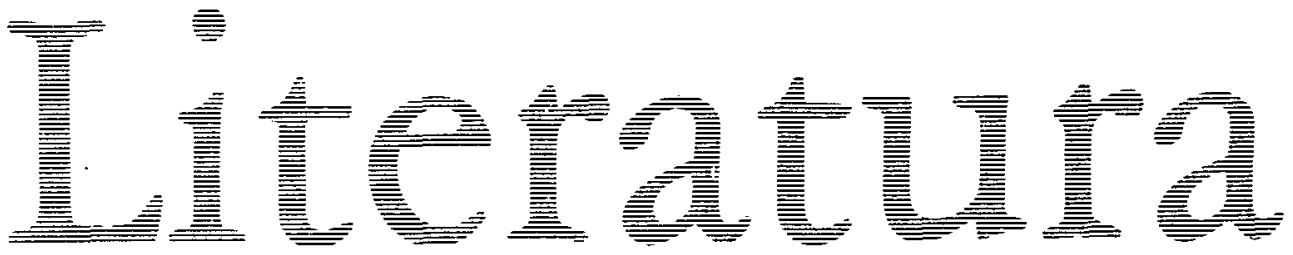

\title{
Lo que todo principiante debe saber y nunca se atrevió a preguntar
}

\section{José Miguel Fernández Dols}

En los núms. 5/6 de Estudios iniciamos una serie de comentarios que pretendían proporcionar algunas indicaciones útiles para el psicólogo bisoño a la hora de organizar su biblioteca personal.

Veíamos entonces que una «biblioteca» no sólo contiene libros, sino todo tipo de «unidades documentales», definidas como un documento (libros, revistas, fichas, etc.; cualquier soporte material de datos) o el conjunto de datos que describe un documento (Wersig y Neveling, 1976).

Hemos dedicado la primera parte de este recetario a lo que llamamos unidades documentales básicas, generalmente obras de referencia que merece la pena poseer. Sin embargo, el conocimiento de una ciencia no consiste en la adquisición de saberes concretos a partir de ciertos textos básicos, sino más bien en la habilidad para utilizar los ingentes archivos que constituyen el «saber científico». Una obra recientemente traducida sobre Teoría de la Ciencia (Ziman, 1981) ilumina la íntima relación entre «hacer ciencia» $\mathrm{y}$ «saber ciencia» incluso en las tareas de documentación:

«En la frontera de la investigación el conocimiento científico está sin contrastar, sin seleccionar, es contradictorio y aparentemente caótico (...). El saber de los libros de texto es una pequeña fracción de lo que se sabe (...). Frente a una cuestión científica contemporánea $(. .$.$) leemos (. .$.$) con la esperanza de lograr una$ valoración consensual de los diversos puntos de vista.»

Nuestra biblioteca debe reflejar tal actividad y, por tanto, debe ser algo más que un conjunto de obras clásicas de consulta. Así, pues, en esta segunda entrega veremos algunas cuestiones elementales sobre la utilización de aquellas unidades documentales que debemos leer, 
pero que no debemos adquirir sino más bien reconvertir, sintetizándolas, en unidades documentales asequibles.

Es preciso subrayar que una unidad documental no debe ser inasequible exclusivamente por su rareza; la dificultad de obtención de un documento es, casi siempre, relativa y solucionable con un poco de paciencia (consulte esta misma sección en el núm. 4 de Estudios).

Una unidad documental es, realmente, inasequible cuando, teniendo en cuenta la razón eficacia/costos, su «precio» global de adquisición no nos es, monetaria e intelectualmente, interesante; el problema radica en el tiempo y el dinero que estemos dispuestos y merezca la pena invertir.

Ciertas unidades documentales deben ser utilizadas in situ, fuera de nuestra propia biblioteca, sin caer en la tentación de comprarlas, robarlas o fotocopiarlas (Umberto Eco habla, muy acertadamente, de nuestra tendencia compulsiva a la acumulación de fotocopias, jamás leídas, como una especie de neocapitalismo intelectual). Abandonando el calor hogareño de su despacho o gabinete, el psicólogo debe ir a menudo de expedición bibliófaga en busca de aquellas monografías, artículos, etc., que debe conocer pero no adquirir.

Hay dos escenarios naturales para tales expediciones: los centros de documentación y las bibliotecas.

Un centro de documentación almacena y proporciona diversos documentos. Tales documentos pueden o no estar presentes en el centro de documentación. Lo usual es que no se encuentren materialmente allí, sino que se nos proporcionen los datos bibliográficos de los documentos solicitados $y$, sólo posteriormente, una reproducción o ejemplar del documento, pedido en préstamo a una biblioteca. Como se ve, el centro de documentación tiene una finalidad primordialmente informativa, nos proporciona los datos sobre las unidades documentales que podemos utilizar sobre un tema dado.

Una biblioteca (Wersig y Neveling, 1976) es una colección organizada de materiales impresos cuya finalidad es facilitar su utilización de acuerdo con las necesidades de sus clientes. Si bien todos sabemos definir intuitivamente una biblioteca, conviene subrayar su dimensión primordialmente utilitaria: aunque produzca rubor decirlo (por lo elemental que es), la biblioteca de un centro de investigación y docencia debería ser el principal lugar de trabajo de investigadores y estudiantes (Litton, 1971). En España participamos de modelos de documentación decimonónicos en los que se valora más la posesión individual que la utilización colectiva.

El centro de documentación es, a pesar de su función informativa, un servicio que, paradójicamente, sólo debe utilizarse cuando se tiene un dominio suficiente de nuestro objeto de estudio y su terminología, ya que los sistemas de obtención de información son relativamente sofisticados. Al margen de las tareas estrictamente características de un centro de documentación, un servicio de este tipo suele permitir su utilización como biblioteca para la consulta de diversas unidades documentales especializadas en la ordenación (por materias, autores, 
etcétera) y síntesis de los datos bibliográficos de la literatura científica (abstracts, índices de sumarios, etc.).

Centros de documentación dedicados a la Psicología o áreas asistenciales afines son el Instituto de Información y Documentación en Ciencias Sociales y Humanidades (Vitrubio, 4, Madrid), el SIIS (especializado en deficiencia mental; en Orense, 12, Madrid) o el centro del INSERSO (María de Guzmán, 52, Madrid).

En cuanto a las bibliotecas, las facultades o secciones de Psicología más importantes del país procuran mejorar sus dotaciones. Sin miedo a parecer centralistas, quizá la más recomendable sea la de la Facultad de Psicología de la Universidad Complutense (Somosaguas), especialmente a partir de la potenciación de su hemeroteca.

Supuesto que nos enfrentamos, ya aleccionados, a la maraña documental de una biblioteca o un centro de documentación, tenemos que afinar nuestra puntería, elegir los documentos adecuados y «reconvertirlos» en otros nuevos que podamos llevarnos honestamente a nuestras casas $\mathrm{y}$, sobre todo, que nos sean útiles.

Esa nueva unidad documental a la que vertemos el contenido de la fuente consultada en la biblioteca o centro de documentación suele ser la ficha de cartulina de formato $75 \times 125$ ó $100 \times 150$.

En general, es preciso que contemos siempre con dos tipos de ficha. La ficha bibliográfica es aquella en la que consignamos los datos de la unidad documental cuya localización puede ser importante en el futuro (deberemos especificar autor, título, publicación o editorial, fechas, etc.). La ficha de trabajo sirve para condensar precisa y sintéticamente contenidos concretos de las unidades documentales consultadas.

La posibilidad de ordenar las fichas para que luego nos sean accesibles hace superior este recurso al manejo indiscriminado de otras notas (ej. folios) que no proporcionan las posibilidades materiales (tamaño normalizado) y formales (sistemas de archivo) de las fichas (vid. Fdez. Dols y Ortega, 1979). La base ideal para la utilización de estas unidades documentales es un fichero por autores y otro temático.

La confección de categorías temáticas para ordenar el fichero es un problema técnico presente en toda obra de documentación. En todo caso, es aconsejable que las categorías sean excluyentes entre sí, i.e., que el criterio de inclusión no sea ambiguo. Además, las categorías excesivamente amplias o ajustadas a los cánones académicos no suelen ser las más adecuadas para el trabajo concreto del profesional.

Algunas publicaciones editan ficheros impresos con los datos de los artículos y su resumen; tal es el caso de los Index Cards del Journal of Applied Bebavior Analysis (solicitudes: M. L. Wright, JABA Department of Human Development, University of Kansas, Lawrence, Kansas 66045). Incluso algunas editoriales envían sus catálogos comerciales con el formato de un fichero (por ej.: Wiley; Baffins Lanes, Chichester, Sussex P019 1UD, England).

Por lo demás, es conveniente articular algún fichero especial que 
puede constituirse en un conjunto de unidades documentales secundarias especialmente útiles; tales ficheros dependen en gran medida de las necesidades e imaginación de cada cual, pero hay tres que, con toda seguridad, pueden facilitar mucho el trabajo:

a) Construya un fichero de todos los trabajos académicos, investigaciones y casos que vaya realizando a lo largo de su vida estudiantil y profesional; en las fichas deberá figurar una referencia numérica o de cualquier otro tipo que le permita localizar tales trabajos en su archivo. Este pequeño dispositivo documental facilitará la coherencia de su producción e impedirá que pierda el tiempo reelaborando información ya asimilada anteriormente.

b) Cuente con un fichero en el que, a semejanza de un catálogo de publicaciones periódicas, aparezcan ordenados alfabética o temáticamente los títulos de las principales revistas técnicas que debe utilizar, con indicación de las bibliotecas en que se localiza y, sobre todo, los números y volúmenes que se encuentran en cada una de ellas. Saber con seguridad qué ejemplares podemos encontrar en cada lugar, puede ahorrarnos muchas paseos inútiles en busca del deseado artículo.

c) Reproduzca los sumarios o índices de los principales manuales, textos o series de su especialidad que no sean asequibles directamente. Indique en cada reproducción el lugar o lugares en donde pueden consultarse. Los sumarios presentan el contenido de la obra en poco espacio; podrá así tener una información que facilitará posteriores consultas.

\section{Referencias}

Eco, U., Come si fa una tesi di laurea, Milán, Bompiani, 1977.

Fernández Dols, J. M., y Ortega, J. E., Introducción a la documentación en Psicología, Madrid, U.A.M., 1979.

Fernández Dols, J. M., y ORTEgA, J. E., Fuentes documentales en Psicología, Madrid, Debate, 1980.

Litron, G., La documentación, Buenos Aires, Bowker, 1971.

Ortega, J. E., y FernándEZ Dols, J. M., «Encuentros en diversas fases», en Estudios de Psicología, 1981, núm. 4, pp. 128-131.

Wersing, G., y Neveling, U. (eds.), Terminología de la documentación, París, Unesco, 1976.

Ziman, J., La credibilidad de la ciencia, Madrid, Alianza, 1981. 